\title{
There are no fish here: public perception of fish stock dynamics
}

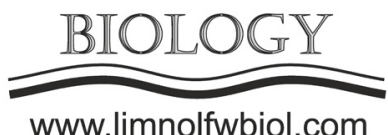

\author{
Interesova E.A. ${ }^{1,2}$, Rakhmanova L.Y. ${ }^{3}$, Kolesnichenko L.G. ${ }^{1}$ \\ ${ }^{1}$ Tomsk State University, Lenin str., 36 Tomsk, Russia \\ ${ }^{2}$ Novosibirsk branch of Russian Federal «Research Institute of Fisheries and Oceanography», Pisareva str., 1, Novosibirsk, Russia \\ ${ }^{3}$ National Research University Higher School of Economics, 28 Promyshlennaya str., Saint-Petersburg, Russia
}

\begin{abstract}
In Western Siberia, the prevailing opinion among local people is that the state of fish resources in the region is decreasing. However, the fish catch statistics shows that only valuable fish species (Siberian sturgeon, sterlet, muksun, nelma) are decreasing, but not ordinary ones (ide, roach, dace, perch, pike). Thus, the Siberian fishermen interpret the decline of sturgeons and whitefishes as a general decrease in the fish resources of the region.
\end{abstract}

Keywords: Western Siberia, Ob, fish stock, fisheries, public perception

For centuries, fisheries in the settlements and villages of the Middle and Lower $\mathrm{Ob}$ were the basis for the subsistence of local communities, both in prerevolutionary, Soviet and post-Soviet periods. The attitude of fishermen and their families towards fish as a natural resource, its stock dynamics, conservation measures and rights of access to the valueble types of fish are related to the employment structure, demographic situation and the state of social and economic infrastructures in the region. That's why in this report we propose to focus on ideas and interpretations of local people and compare them with official statistics.

To analyze the population's perception of the situation concerning the state of fish stocks in Western Siberia at the present time, in 2018-2019, sociological surveys were conducted in 24 settlements in the basin of the river Ob. 466 people were interviewed.

The analysis of the obtained data showed that among the population of Western Siberia as a whole, the prevailing opinion is that the fish stock is deteriorating. $60 \%$ of the respondents claim that the number of fish has decreased and a very small number of respondents (3\%) believe that the number of fish has increased (Fig. 1). The chart shows that $28 \%$ found it difficult to answer this question: based on a random sample of 100150 people in sparsely populated villages, interviews and questionnaires were also conducted with those members of communities for whom fishing is not their primary source of income.

It is natural that people in settlements with a long history and, accordingly, a fishing tradition, feel a decrease in fish stocks more than residents of cities and villages that arose in Soviet times as a result of the development of Siberian subsurface reserves, such as oil and gas fields in the 1960s - 1970s (Rakhmanova et al., 2019). Differences in the proportion of respondents who believe that the number of fish has decreased are statistically significant (Mann-Whitney test, $\mathrm{p}=$ 0.0093 ) between this two types of settlements. It is also logical that the latter are generally less concerned about this problem - almost $40 \%$ of the respondents found it difficult to answer.

At the same time, the data of fishery statistics indicate that the total legal fishing in the basin of the Middle and Lower Ob (Tomsk and Tyumen regions) over the past 40 years has similar dynamics and (after the decline in fish production in the 1990s, caused to a greater extent by social-political transformations in the country and the collapse of the fishing industry in the region) in the last $15-20$ years, there has been a gradual increase in catches. At present, it has

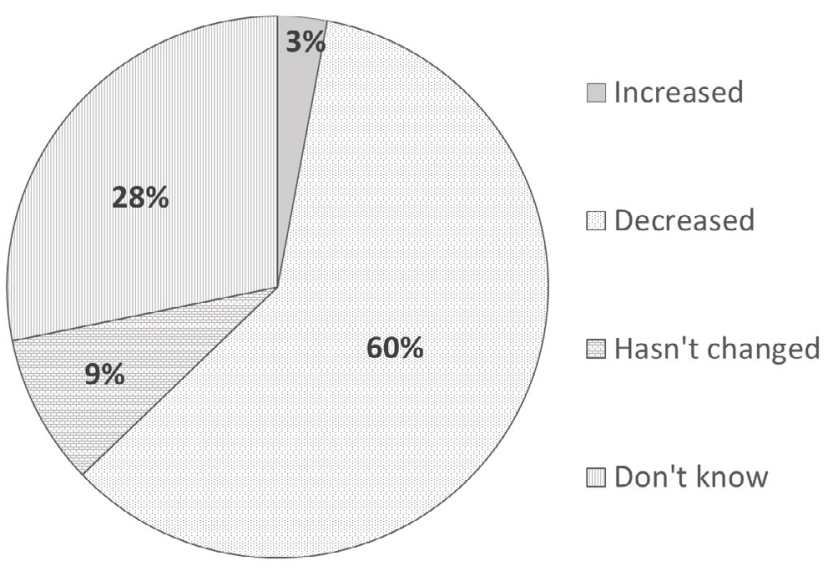

Fig.1. Ratio of population' views on the dynamics of fish stocks in the Tyumen and Tomsk regions

*Corresponding author.

E-mail address: interesovaea@yandex.ru (E.A. Interesova)

(C) Author(s) 2020. This work is distributed under the Creative Commons Attribution 4.0 License. 

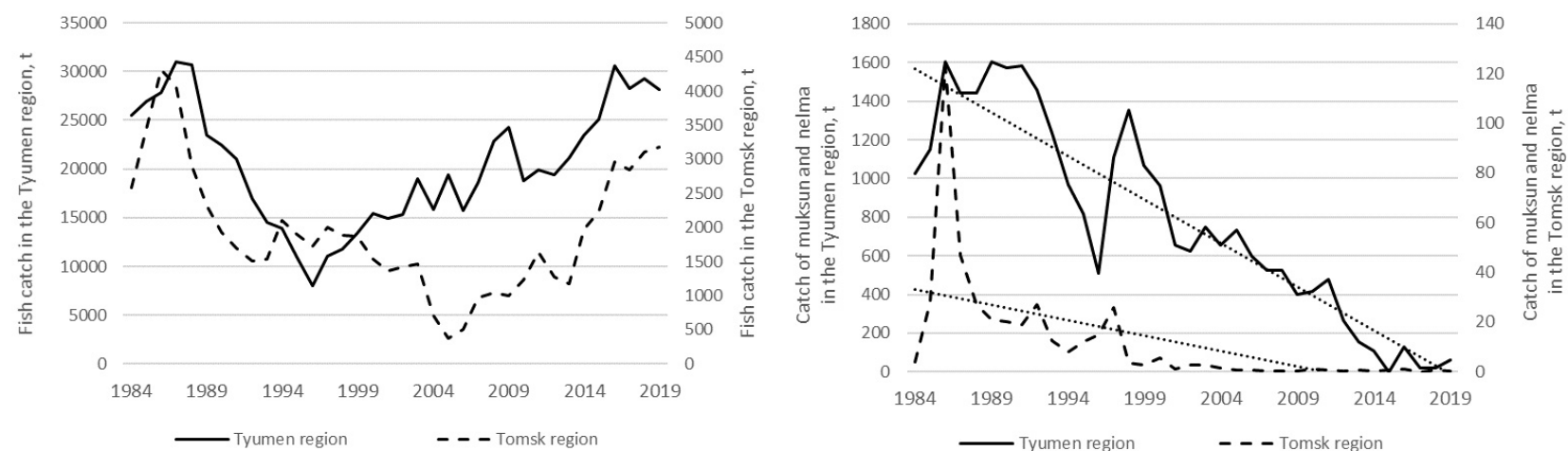

Fig.2. Catch of fish in the Tyumen and Tomsk regions according to the official fishery statistics:

A - the total volume of fish catch; B - the catch of muksun and nelma

practically reached the level of the 1980s (Fig. 2A). Thus, it turns out that the opinion of the population does not correspond with the data on the total legal fishing in the region.

The main volume of fish caught in the Ob basin has always been provided by the so-called ordinary fish species: ide, roach, dace, perch, pike. In recent years, alien fish species, bream and pike perch, introduced into the Ob basin in the second half of the XX century and successfully naturalized in the region, have also acquired great importance in fisheries. The share of valuable fish species (Siberian sturgeon, sterlet, muksun, nelma) has always been insignificant (Rostovtsev and Interesova, 2015), however, these species were especially desirable prey and brought the main income to the population. Unfortunately, their stocks and, accordingly, catch, tend to catastrophically decrease (Fig. 2B).
Thus, it is obvious that the population living in the $\mathrm{Ob}$ river basin, spoilt by an abundance of valuable fish species, perceives the decline in their reserves as a general decrease in the fish resources of the region.

This research was supported by the RFBR, projects 18-00-01654 (K), 18-05-60264, 18-00-01625

\section{References}

Rakhmanova L., Kolesnichenko L., Drozdov V. et al. 2020. Climate change from the arctic people's point of view: rhythms of everyday life, infrastructures and landscapes. In: Pokrovsky O.S., Kirpotin S.N., Malov A.I. (Eds.), The Arctic: current issues and challenges. New-York: Nova Science Publishers, pp. 15-57.

Rostovtsev A.A., Interesova E.A. 2015. Fish resources of Tomsk region. Rybnoe Khoziaystvo [Fisheries] 5: 48-49. (in Russian) 